\title{
Courtenay, William J., Ubl, Karl, Gelehrte Gutachten und königliche Politik im Templerprozeß
}

\section{Mathieu Olivier}

\section{OpenEdition}

\section{Journals}

Édition électronique

URL : http://journals.openedition.org/ifha/6739

DOI : $10.4000 /$ ifha.6739

ISSN : 2198-8943

Éditeur

IFRA - Institut franco-allemand (sciences historiques et sociales)

Référence électronique

Mathieu Olivier, « Courtenay, William J., Ubl, Karl, Gelehrte Gutachten und königliche Politik im

Templerprozeß », Revue de l'IFHA [En ligne], Date de recension, mis en ligne le 01 janvier 2012, consulté le 22 septembre 2020. URL : http://journals.openedition.org/ifha/6739; DOI : https://doi.org/10.4000/ ifha. 6739

Ce document a été généré automatiquement le 22 septembre 2020.

(C)IFHA 


\title{
Courtenay, William J., Ubl, Karl, Gelehrte Gutachten und königliche Politik im Templerproze $\beta$
}

\author{
Mathieu Olivier
}

1 Les dernières années de l'ordre du Temple ont suscité un flot si nourri de publications depuis si longtemps que l'on pourrait s'étonner de prime abord de l'entreprise éditoriale de W.C. et K.U. Une lecture attentive vient dissiper cette première impression. Les trois textes latins réunis dans ce petit volume demeuraient incontestablement mal connus dans le détail. Les deux quaestiones de Jean de Pouilly (Quodlibeta II q. 15 et V q. 19 = textes 1 et 2) relatives à la matière templière sont ainsi éditées pour la première fois, tandis que la transcription intégrale de l'unique témoin de la Consultatio altera (texte 3) vient remplacer avantageusement les éditions tronquées dont on devait se contenter jusque-là. Accompagnés d'un commentaire dense et précis sous forme d'une longue étude liminaire, ces trois textes, empreints d'une véhémence polémique qui transparait au travers des formules convenues, nous plongent au cœur de la fabrique de discours éminemment politiques derrière leur vernis d'érudition, et indissolublement liés à cet épisode passé à la postérité. On ne saurait par ailleurs sous-estimer leur valeur documentaire ponctuelle pour la reconstitution du « procès » des Templiers en ces multiples péripéties du 13 octobre 1307 à la sentence rendue au concile de Vienne. C'est ainsi que, comme le montrent les deux éditeurs au terme d'une argumentation serrée (p. 42-47), les rodomontades de Jean de Pouilly ont toute chance d'être l'unique source procurant à l'historien quelques détails sur une assemblée de prélats réunie à Paris au début de l'année 1309 pour débattre de divers points controversés du dossier templier.

2 Il serait cependant réducteur de ne voir en cette publication qu'un complément d'information bienvenu. Comme le titre du reste l'indique, l'ambition de W.C. et K.U. consistait bien plutôt à réexaminer à la lumière de ces textes la question des liens entre cour royale et Université au tournant des XIIIe et XIVe siècles. Les conclusions présentées au terme de l'étude (p. 62-65) suffisent à montrer que ce dossier constitue à 
cet égard une matière riche d'enseignements pour peu que l'on fasse l'effort de quitter un instant les sentiers battus de la "fin des Templiers ». En cela, le présent travail s'inscrit dans un champ de recherches beaucoup plus vaste qui a connu ces dernières années un dynamisme remarquable : celui du pouvoir de l'expertise au temps de l'essor des Universités.

3 Mathieu Olivier (lycée Dumont-d'Urville, Toulon) 